\title{
Research on industrial design technology innovation -- a case study of ceramic glaze
}

\author{
Shen Haiyong a,1 , Dai Yanyan² and Li Jun ${ }^{1}$ \\ ${ }^{1}$ Shenyang Jianzhu university,college of design and art , 100168, liaoning province shenyang city, China \\ ${ }^{2}$ Shenyang Jianzhu university, center for innovative and entrepreneurship , 100168, liaoning province shenyang, China
}

\begin{abstract}
Taking the technology innovation of ceramic glaze as an example, the innovation of the industrial design technology was analyzed. The way of combining industrial design ideas and design thinking way was put forward. The theoretical connotation of industrial design was broadened. To break with the original industrial design way of thinking, and combined with the practical development of Chinese industrial design, the advanced theory of industrial design was collected, in order to provide constructive suggestions for the theoretical development of industrial design and industrial design education in the future.
\end{abstract}

\section{The development of the industrial design definition}

The first use of the concept of industrial design has a very close relationship with the development of modern manufacturing. The industrial design education originated in German, which first appeared in the early 1920s to develop industrial product design and process in the Bauhaus school in Germany. The peak of the practice and development of industrial design happened in the 1930 s of the United States with full of commercial atmosphere, the time when the company was faced with many problems about industrial design. The Fortune magazine in United States illustrated this well in February 1934 :

"As a phenomenon, the industrial designer, came into being as mass production raised output to where one after another, industries hitherto without benefit of other engineering design found their products matched by other manufacturers and the market consequently glutted"

In that background, industrial design has successfully created the unprecedented product and new market. Different from ordinary products, industrial design helped manufacturers to create products which were fully functional and full of artistic features, conforming to the aesthetic psychology of customers. In the traditional industrial design theory: The most important contribution for industrial design is to make the product different from others through the design of the color and style, or by enhancing the product details and tiny additional functions. The invention of the new technology innovation is known as radical innovation. The industrial design usually uses less radical innovation to design new product, but adds functions through some mature technology. According to the needs of consumers for the product function, existing inventions and technology are applied to the product, make making consumers get more satisfaction in the use of the product, which is the central task of industrial design.

Traditional cognition for the interpretation of industrial design is hard to meet the requirements of today's market for industrial design, so the new interpretation of the industrial design theory was introduced. For the interpretation of the "design" is developed in the direction of being more profound, it is considered to be a thinking ability of humans naturally formed in the long-term evolution, just as humans use language to express their emotions and communicate with others. The Bureau of Labor Statistics in December 2017 issued the Occupational Outlook Handbook, which made such a definition about industrial design: Industrial design should be applied to mass production of industrial products, such as cars, home appliances, and toys. Through the combination of art, business and engineering, products will be used more convenient. Industrial designers should take the function, aesthetics, production costs, and usability of products into consideration when developing new products. Industrial designers should not only work in offices in a variety of industries, but also travel frequently to testing facilities, design centers, clients' exhibit sites, users' homes or workplaces, and places where the product is manufactured.

Contemporary industrial design as a kind of design services, is committed to create new value growth of the products for enterprise. Before the industrial revolution, 
the cognition of design stayed in craftsman' thinking on handiwork and production process. In the industrial age, we need to be more professional in the division of labor and the accumulation of professional knowledge. At present, the industrial design activities usually take part in the process of the development of new products, including the following characteristics: (1) New products should be created, of which the design styles reach or exceed that of the existing products. (2) The created new products should be the integration and application of new technology. (3) Industrial design activities can improve the sales of products or to create new markets. (4) Design behavior can strengthen and protect the product brand. Innovation has become an integral part of the contemporary industrial design, which includes the following three categories: (1) incremental innovation and improvement of design. (2) all kinds of product style innovation.(3) radical new function of innovation.

At present, the most important skills and qualities of the industrial design are summarized into seven aspects, which can be divided into dominant and hidden qualities. Dominant qualities are more specific skills, while hidden quality is more abstract, which can not be improved through short-term training. For a qualified industrial designer, the following aspects of quality are necessary.

\section{Dominant quality requirements:}

(1) Artistic ability: Industrial designers need to quick express their design ideas. Therefore, the designer must express their ideas quickly through the skill of hand drawing.

(2) Computer skills: Industrial designers need to create design and prototype through the aided design tool of computer. In particular, industrial designers need to master the two-dimensional computer-aided drawing software to draw a quick sketch, and three-dimensional modeling software to build a three-dimensional model.

(3) Mechanical skills: Industrial design must understand how to manufacture the new product, at least understand the manufacturing process of his industry.

\section{Hidden quality requirements:}

(1) Creativity: This kind of creativity is not an unconstrained style, and industrial designers must have enough creativity to integrate existing technologies and new products . This requires designers to understand the present technology very well.

(2) Analytical skills: Industrial designers need to study the behavior of user through logic and reasoning skills to define the demand for the new product. In particular, industrial designers need to imagine a scene that users use a product, analyze users' behavior, thus provide background support for the design.

(3) Interpersonal skills: Industrial designers need cooperation with customers, as well as the domain expert, so they need to have the ability to cooperate with others. Specifically, industrial designers should discuss the feasibility with researchers, engineers and customers.

(4) Problem - solving skills: Industrial designers decide the product function, size, shape, and even costs. Designers need to consider function, aesthetic, cost, and usability. How to balance art, business and engineering to make the products much easier to be uses is a great test for designers' problem-solving ability.

Industrial design is a typical representative of multidisciplinary cross. Technology determines whether a product idea is feasible, business determines whether a product idea has market potential, while the man-machine factor determines the availability of the product ideas. Industrial designers is an innovative design industry under the background of certain design conditions. Industrial design is a kind of art behavior, which can't be subjectively expressed completely like traditional art. Industrial design contains the science theory and mechanical principle, but it's required to do more to deal with the relationship between people and things. Because industrial design is a multidisciplinary cross, industrial designers are required to have a number of skills and qualities.

\section{The innovation research of ceramic glaze}

Ceramic glaze decides the physical and chemical properties of ceramic materials, which also affects the result of colour and surface. In China's song dynasty, the five famous kilns have different glaze color. In British the outstanding achievement of Wedgwood series ceramics is about glaze. Taking the innovation of ceramic glaze as an example, research on technological innovation of the industrial design can make us more aware of the importance of the technological innovation in contemporary industrial design.

The classification method of oxide is based on understanding of the chemical composition of ceramic glaze. In this way, we can calculate the high temperature melting temperature of ceramic materials and the relationship among materials in high temperature chemical reaction. First of all, the ceramic glaze is supposed to be completely melted, and only contain the oxide, which is from their raw materials by mixing and melting. This kind of raw material needs to use the oxide classification calculation method to represent the relative amounts of each oxide in the glaze. The kind of raw materials should be decided so that the species and components can be obtained in glaze.

The oxide can be divided into three terms:

RO: $\mathrm{PbO}, \mathrm{Na}_{2} \mathrm{O}, \mathrm{K}_{2} \mathrm{O}, \mathrm{ZnO}, \mathrm{CaO}, \mathrm{MgO}, \mathrm{BaO}, \mathrm{Li}_{2} \mathrm{O}$

$\mathrm{R}_{2} \mathrm{O}_{3}: \mathrm{Al}_{2} \mathrm{O}_{3}, \mathrm{~B}_{2} \mathrm{O}_{3}$

$\mathrm{RO} 2: \mathrm{SiO}_{2}$

In the calculation method, RO oxide is the glaze flux to promote melting in silica glass, which has very strong inhibitory effect on melting. Aluminium oxide, helpless in the oxide melting, has an effect on the reaction with the alkaline action. This kind of oxide classification method gives clear definition on the role of various oxides in molten glaze. All the RO oxides, naturally are not equal in terms of flux activity, but the effect is the same, which can promote the melting through the corrosion of Silicon dioxide.

The characteristics of high temperature liquid metal crystalline glaze: Generally, when the glaze is cooling, it is still a kind of material that is amorphous and 
non-crystalline However, under special circumstances, the glaze can be crystallized during cooling process, and produce various forms of the crystalline glaze. The ordinary glaze contains alumina, which can not only prevent the glaze from crystallizing, but also increase the consistency to avoid the glaze over flowing. To cooperate with crystalline glaze, the composition of alumina is bound to greatly reduce, usually no more than 0.1 molecular equivalent, of which it is only a third in high temperature glaze. In many kinds of crystalline glaze, there is no alumina. Without Alumina, the glaze often over flows. When manufacturing crystalline glaze ware, flow glaze should be prepared, while at ordinary times the vessels are set on the porcelain clay round cakes. High content zinc oxide is conducive to the development of crystalline glaze. In crystalline glaze, the situation that there is about 0.3 equivalent of zinc is very common, while rutile or titanium oxide also promotes the development of crystallization. As for the basic glaze, lead oxide, alkaline metal or boron can be used as solvent. The alkaline glaze is often used. Because there are a large number of zinc and rutile, the crystalline glaze is a little opaque. Because no or low alumina, the glaze flows and shine. The crystal in the glaze may be very small with a cluster of clusters, or may be large with spectacular appearance. With coloring oxides, such as copper oxide or cobalt oxide, the crystal will appear to be magnificent in the glaze color. The firing process is the decision factor in the production of crystal in glaze. When heating, it can be carried out in accordance with the usual speed, but when cooling, it can not be cooled fast but slowly to a point so that the materials in the glaze can have a tendency to crystallize. The temperature at this point is usually lower than the highest temperature, but higher than the glaze curing temperature. The reaction temperature of the crystalline glaze must be tested to determine. If the composition of glaze is right, at a certain temperature stage, slow cooling can produce a large number of crystal.

The development and application of ceramic glaze has important practical significance for the development of ceramic materials. The characteristics of ceramic crystalline glaze are high strength, moisture proof, fire prevention, acid-proof, alkali resistance, frost resistance, not aging, not metamorphosed, not fade, easy to clean, etc., and it has a rich artistic adornment effect. There is a layer of vitric glaze on the surface of high-temperature glaze of architectural ceramics, which is waterproof, decorative, clean and durable. With metal oxide and natural minerals as colorants, high temperature glaze is decorated on the embryo, which, after high temperature of 1280 degrees' heating, naturally turns out to be colored ceramics, and has high artistic value.

Industrial design technology innovation provides the technical support for the development of industrial design, further widening the idea of design. Up to now, for the development of industrial design, the designer can not be merely content with common-sense understanding of the existing technology, but more deeply understand the technical details of the features and make a breakthrough in the technology. Innovative design thinking is one of the important directions of the future development and application of industrial design. Industrial designers need to know how to use creative design thinking to make technical innovation.

\section{The characteristics and essence of design thinking}

In many areas, the production and accumulation of theory is through practice. Knowledge is derived from production, in turn, production is used to assess the accuracy of knowledge. Creative people tend to work in two different ways at the same time: as the discoverer of the problem and problem solvers. As discoverer, they have unique curiosity and keen observation power for the unknown. These drives them to find reasonable explanation and the answer to the question. As part of the solvers, they have strong creativity, and they can analyze and synthesize the structure, arrangement, patterns, composition, and concept of the problem based on the existing data. Due to the difference of thinking process, the problem discoverer and solver may be different in thinking and working. In addition, the way of thinking and working may be affected by the difference of majors, research areas, and other factors, but all these will help us to define the essence of innovation design thinking. One of the common features is the practical work.

At present, there is no concrete answers to the essence of creative design thinking, and what makes a person become the creative design thinking, .But we can learn the cognitive way and thinking method of innovative designers according to the characteristics of the known creative design thinking. These features help us to understand the essence of innovation design thinking. In addition to the qualities that innovative designers should have, innovative design itself also has several unique processes.

\begin{tabular}{|c|c|}
\hline Characteristics & Description \\
\hline $\begin{array}{l}\text { Human- and } \\
\text { environment-centered } \\
\text { concern }\end{array}$ & $\begin{array}{l}\text { Designers must continually consider and } \\
\text { satisfy what is needed for the development of } \\
\text { humans }\end{array}$ \\
\hline Ability to visualize & Designers work visually. \\
\hline $\begin{array}{l}\text { Multifunction } \\
\text { tendencies }\end{array}$ & $\begin{array}{l}\text { Designers should look at different solutions to } \\
\text { a problem and keep the problem in mind. }\end{array}$ \\
\hline Systemic vision & $\begin{array}{l}\text { Designers should treat problems as system } \\
\text { problems with opportunities for systemic } \\
\text { solutions involving different procedures and } \\
\text { concepts. }\end{array}$ \\
\hline $\begin{array}{l}\text { Ability to use language } \\
\text { as a tool }\end{array}$ & $\begin{array}{l}\text { Designers should be able to verbally explain } \\
\text { their creative process and invention, when } \\
\text { details and relationships can not be visually } \\
\text { expressed. }\end{array}$ \\
\hline Affinity for teamwork & $\begin{array}{l}\text { Designers need to develop interpersonal skills } \\
\text { that allow them to communicate across } \\
\text { disciplines and work with other people. }\end{array}$ \\
\hline $\begin{array}{l}\text { Avoiding the } \\
\text { one-sidedness of choice }\end{array}$ & $\begin{array}{l}\text { Designers search competing alternatives } \\
\text { before moving to choice making or decision } \\
\text { making. } \\
\text { They try to find ways to come up with new } \\
\text { configurations. This process can help to find } \\
\text { an optimum solution, avoiding the } \\
\text { one-sidedness of choice. }\end{array}$ \\
\hline
\end{tabular}

One characteristic of innovative design thinking is iterations of the design process (iterations: repeat 
feedback process activities, and its purpose is usually to approximate the required target or result), as well as the exploratory, and sometimes a chaotic process. Innovative design thinking starts from some abstract specifications, and some will develop into a "briefing". These briefings are used to describe a final product, and gradually optimize the product details. In the process of creative design thinking, the conflict between product descriptions and details may happen. Design details of the requirements may change design, or find unexpected problems in the design process. In this case, the design should follow the adjustment cycle between detail requirements and solutions, until the final solution is reached.

\section{References}

1. "Industrial Designers" in Fortune magazine 1934

2. Caplan. Ralph, [1982] By Design. St Martins Press; New York.

3. Dumas, Angela, and Mintzberg, Henry, [1989] "Managing Design Designing Management"in Design Management Journal.

4. Dumas, Angela, and Fentem, Andrew, [1998] "Totemics: New Metaphor Techniques tomanage Knowledge from Discovery to Storage and Retrieval. In Technovation.

5. Graham, Pauline, [1996] Mary Parker Follett, Prophet of Management, Harvard Business School.

6. "product design hand-painted techniques", [Netherlands] Stael China youth press

7. "Chinese fine arts history" Shen Haiyong southwest normal university press

8. "Innovation design thinking" Lu Bainian Tsinghua university press.

9. "Design thinking innovation guide" Wang Keyue etc. Tsinghua university press.

10. "15 seconds illustrations and 30 seconds sketch" Yamada Tian Yafu ,Liaoning cience and technology press

11. "Understanding and innovation: an experience of product design thinking",Shen Jie, Jiangsu fine arts publishing house

12. "product design and development" magazine, Wang Xuanzheng, Jiangxi fine arts publishing house

13. Paper discussed shallowly product innovation design "huina" enterprise "in 2012 we

14. Thesis "talk about the development trend of art design history studies of literature and art, Chen

15. Shou-zhi wang. "the world modern design history of the China youth press, 2002. 